
\title{
$\begin{array}{ll}\text { Research Square } & \begin{array}{l}\text { Preprints are preliminary reports that have not undergone peer review. } \\ \text { They should not be considered conclusive, used to inform clinical practice, } \\ \text { or referenced by the media as validated information. }\end{array}\end{array}$
}

\section{Bibliometric analysis on randomized controlled trials of colorectal cancer over the last decade}

Jun-hong Hu ( $\nabla$ hjh-8282@163.com )

Henan University https://orcid.org/0000-0003-2590-6784

Chen-Yu Wang

Henan University

Shi-Can Zhou

Henan University

Xing-Wang Li

Henan University

Bing-Hui Li

Henan University

Jun-jie Zhang

Henan University

Zheng Ge

Henan University

Quan Zhang

Henan University

\section{Research}

Keywords: Colorectal Cancer, Randomized Controlled Trial, Bibliometrics

Posted Date: February 12th, 2020

DOI: https://doi.org/10.21203/rs.2.23370/v1

License: (c) (i) This work is licensed under a Creative Commons Attribution 4.0 International License.

Read Full License 


\section{Abstract}

Background The aim of this bibliometric analysis was to evaluate the clinical trials of randomized controlled trials (RCTs) of colorectal cancer all the world over the past decade.

Methods The PubMed and Web of Science database were searched to obtain a randomized controlled trial of colorectal cancer from January 1, 2008 to January 1, 2018. The included literatures were analyzed with the bibliometric analysis.

Results In the past 10 years, Randomized controlled trials of colorectal cancer have shown an upward trend; Most of the top ten research institutions in the literature are from the USA, the UK and other regions which has the high incidence of colorectal cancer; Most of the related research journals are also sponsored by European and American countries; the frequently cited top 15 literatures are mostly international multi-center clinical research, and there are fewer participants in Chinese research institutions. By keyword co-occurrence, colorectal cancer research mostly involves screening, disease-free survival, drug treatment, surgical methods, clinical trials, quality of life and prognosis; The results of the co-authorship network analysis show that Chinese researchers are less involved in international cooperation.

Conclusions High-quality randomized controlled trials are increasingly favored by top international journals. However, there is still a large gap in clinical research between China and abroad. Researchers should gradually implement the standardization and accuracy of clinical trials, strengthen international multi-center cooperation and emphasize quality control.

\section{Background}

In the past 10 years, with the basic theoretical research on the pathogenesis and molecular level of colorectal cancer deepening, the clinical research on colorectal cancer has also made significant progress, but the incidence of colorectal cancer is still increasing year by year ${ }^{[1]}$, its incidence in China has risen to the $5^{\text {th }}$ in malignant tumors ${ }^{[2]}$, and breakthrough research on prevention, screening, diagnosis and treatment of colorectal cancer is still lacking. In recent years, clinical drug trials and evidence-based medicine have provided a solid source of evidence for the development of clinical practice guidelines and the promotion of new drugs, but international clinical guidelines such as the National Comprehensive Cancer Network (NCCN) and Europe. The European Society for Medical Oncology (ESMO) clinical guidelines for treatment are rarely available in clinical studies from China. However, at present, the enthusiasm of domestic clinicians for conducting randomized controlled trials (RCTs) is high, but most of them are difficult to determine valuable research directions. The systematic methodological knowledge is still lacking, especially for important links. Insufficient levels, such as rigorous ethical review, scientific design and a lot of manpower, financial and time costs, make it difficult to obtain high-quality research results. Therefore, in order to evaluate the research status of colorectal cancer RCT at home and abroad, 
this paper uses bibliometric analysis to analyze, in order to provide reference for the design, cooperation and implementation of colorectal cancer RCT in China.

\section{Methods}

\section{Eligibility criteria}

Inclusion criteria: colorectal cancer RCT study; time range from January 01, 2008 to January 01, 2018. Exclusion criteria: repetition, excerpt, conference papers, monographs, retraction, errata, etc.

\section{Search}

The computer retrieved articles from the PubMed and Web of Science databases from January 01, 2008 to January 1, 2018. The search terms are: colorectal, rectal, rectum, colonic, colon, neoplasm, cancer, tumor, adenocarcinoma, randomized controlled trial, and the like.

\section{Data extraction}

The searched literature was independently screened and extracted by two investigators. The extracted information includes the author, the year of publication, the country in which it is located, the research institution, the cited situation, and the publication. In case of disagreement, it will be resolved through consultation with the third researcher.

\section{Data analysis}

Descriptive statistical analysis using Microsoft Excel 2013 software; descriptive analysis of organizational distribution, journal distribution and citation of published literature; visual analysis using VOSviewer 1.6.4 software, mapping of keyword co-occurrences and co-authors Relationship network diagram.

\section{Results}

\section{Research screening process and results}

Pubmed detected 3,146 articles, Web of science detected 4,539 documents, removed 1029 duplicate articles, read basic information such as texts and abstracts, excluded 17 informal publications, and 324 articles unrelated to colorectal cancer. The types were 185 articles such as news, conference abstracts, monographs, excerpts, retractions, and errata, and 4575 non-randomized controlled trials, eventually including 1555 articles. The literature screening process and results are shown in Figure 1.

\section{Basic characteristics of the included literature}


Between 2008 and 2018, the number of literatures on colorectal cancer RCT studies showed a gradual increase (Figure 2).

\section{RCT literature published regional and institutional distribution}

The top ten countries that publish relevant literature and their numbers are shown in

Figure 3. The top ten research institutions that publish relevant literature are listed in Table 1.

Table 1 The top ten research institutions publishing literature

\begin{tabular}{lcc}
\hline Institution & Country & Number \\
\hline Harvard University & USA & 52 \\
University of California & USA & 51 \\
University of Texas & USA & 41 \\
University of London & English & 40 \\
University of Toronto & Canada & 33 \\
Boston Healthcare system & USA & 30 \\
NIH National Institute of Health & USA & 29 \\
University College London & English & 25 \\
National Cancer Institute NCI & USA & 24 \\
Mayo Clinic & USA & 24 \\
\hline
\end{tabular}

\section{Journal distribution and Cited situation}

According to the number of RCTs the journals was sorted. Most of the journals are concentrated on the fields of cancer, immunity, gastrointestinal surgery, etc. The journals that contain more RCT literatures usually have the higher impact factor. Meanwhile, highquality journals are more interested in high-level clinical research like RCT. According to the publication volume, the top 20 journals are shown in Table 2.

Table 2 Top 20 journals publishing the literature 

literature

\begin{tabular}{cccc}
\hline Journal of clinical oncology & 84 & 26.3 & USA \\
Annals of oncology & 69 & 13.93 & English \\
\hline BMC Cancer & 55 & 3.29 & English \\
\hline The Lancet Oncology & 49 & 36.42 & USA \\
\hline Trials & 42 & 2.07 & English \\
\hline European journal of cancer & 38 & 7.19 & English \\
\hline British journal of Surgery & 36 & 5.43 & English \\
\hline International journal of colorectal & 32 & 2.53 & Germany \\
disease & & & \\
\hline British journal of cancer & 32 & 5.92 & English \\
\hline Annals of surgery & 32 & 9.2 & USA \\
\hline Diseases of the colon and rectum & 28 & 3.62 & USA \\
\hline Colorectal Disease & 28 & 6.78 & English \\
\hline Cancer & 26 & & USA \\
\hline Chinese Journal of Gastrointestinal & 23 & & \\
\hline Surgery & & 3.12 & USA \\
\hline Surgical endoscopy & 23 & 3.86 & USA \\
\hline Clin Colorectal Cancer & 21 & 53.25 & English \\
\hline Lancet & 17 & 2.89 & English \\
\hline Cancer epidemiology & 17 & 17.02 & English \\
\hline Gut & 15 & 2.41 & English \\
\hline BMJ Open & 15 & &
\end{tabular}

Among all the relevant literatures, the top three are from the top comprehensive journal of clinical medicine, LANCET. Others are from authoritative journals in various clinical fields. The higher-level clinical research from the authoritative journal has higher recognition. According to the cited situation, the top 15 literatures are shown as Table 3.

Table 3 Top 10 literatures cited in the domestic and international publication of colorectal cancer RCT related literature in 2007-2018 


\begin{tabular}{|c|c|c|c|c|}
\hline Author & Title & Journal & Cited & Year \\
\hline $\begin{array}{l}\text { maughan, } \\
\mathrm{TS}^{[3]}\end{array}$ & $\begin{array}{l}\text { Perioperative chemotherapy with FOLFOX4 and surgery versus } \\
\text { surgery alone for resectable liver metastases from colorectal } \\
\text { cancer (EORTC Intergroup trial 40983): a randomised controlled } \\
\text { trial }\end{array}$ & LANCET & 1104 & 2008 \\
\hline $\begin{array}{l}\text { Atkin, } \\
\mathrm{WaS}^{[4]}\end{array}$ & $\begin{array}{l}\text { Once-only flexible sigmoidoscopy screening in prevention of } \\
\text { colorectal cancer: a multicentre randomised controlled trial }\end{array}$ & LANCET & 961 & 2010 \\
\hline $\begin{array}{l}\text { Grothey, } \\
\mathrm{A}^{[5]}\end{array}$ & $\begin{array}{l}\text { Regorafenib monotherapy for previously treated metastatic } \\
\text { colorectal cancer (CORRECT): an international, multicentre, } \\
\text { randomised, placebo-controlled, phase } 3 \text { trial }\end{array}$ & LANCET & 935 & 2013 \\
\hline Tol, J ${ }^{[6]}$ & $\begin{array}{l}\text { Chemotherapy, Bevacizumab, and Cetuximab in Metastatic } \\
\text { Colorectal Cancer }\end{array}$ & $\begin{array}{l}\text { NEW } \\
\text { ENGLAND } \\
\text { JOURNAL OF } \\
\text { MEDICINE }\end{array}$ & 904 & 2009 \\
\hline $\begin{array}{l}\text { Baxter, } \\
\mathrm{NN}^{[7]}\end{array}$ & Association of Colonoscopy and Death From Colorectal Cancer & $\begin{array}{l}\text { ANNALS OF } \\
\text { INTERNAL } \\
\text { MEDICINE }\end{array}$ & 835 & 2009 \\
\hline $\begin{array}{l}\text { Hecht, } \\
\mathrm{JR}^{[8]}\end{array}$ & $\begin{array}{l}\text { A Randomized Phase IIIB Trial of Chemotherapy, Bevacizumab, } \\
\text { and Panitumumab Compared With Chemotherapy and } \\
\text { Bevacizumab Alone for Metastatic Colorectal Cancer }\end{array}$ & $\begin{array}{l}\text { JOURNAL OF } \\
\text { CLINICAL } \\
\text { ONCOLOGY }\end{array}$ & 596 & 2009 \\
\hline $\begin{array}{l}\text { Maughan, } \\
\operatorname{TS}^{[9]}\end{array}$ & $\begin{array}{l}\text { Addition of cetuximab to oxaliplatin-based first-line combination } \\
\text { chemotherapy for treatment of advanced colorectal cancer: } \\
\text { results of the randomised phase } 3 \text { MRC COIN trial }\end{array}$ & LANCET & 574 & 2011 \\
\hline $\begin{array}{l}\text { Peeters, } \\
\mathrm{M}^{[10]}\end{array}$ & $\begin{array}{l}\text { Randomized Phase III Study of Panitumumab With Fluorouracil, } \\
\text { Leucovorin, and Irinotecan (FOLFIRI) Compared With FOLFIRI } \\
\text { Alone As Second-Line Treatment in Patients With Metastatic } \\
\text { Colorectal Cancer }\end{array}$ & $\begin{array}{l}\text { JOURNAL OF } \\
\text { CLINICAL } \\
\text { ONCOLOGY }\end{array}$ & 549 & 2010 \\
\hline $\begin{array}{l}\text { Folprecht, } \\
\mathrm{G}^{[11]}\end{array}$ & $\begin{array}{l}\text { Tumour response and secondary resectability of colorectal liver } \\
\text { metastases following neoadjuvant chemotherapy with cetuximab: } \\
\text { the CELIM randomised phase } 2 \text { trial }\end{array}$ & $\begin{array}{l}\text { LANCET } \\
\text { ONCOLOGY }\end{array}$ & 523 & 2010 \\
\hline $\begin{array}{l}\text { Verwaal, } \\
\mathrm{VJ}^{[12]}\end{array}$ & $\begin{array}{l}\text { 8-year follow-up of randomized trial: Cytoreduction and } \\
\text { hyperthermic intraperitoneal chemotherapy versus systemic } \\
\text { chemotherapy in patients with peritoneal carcinomatosis of } \\
\text { colorectal cancer }\end{array}$ & $\begin{array}{l}\text { ANNALS OF } \\
\text { SURGICAL } \\
\text { ONCOLOGY }\end{array}$ & 448 & 2008 \\
\hline
\end{tabular}

\section{Keyword co-occurrence and co-authored network}


VOSviewer software was used to draw a keyword co-occurrence map, it can be seen that age, surgery, drug therapy, targeted therapy, neoadjuvant, pathology, comparative study, treatment outcome, disease-free survival, quality of life and other keywords appear frequently (Figure 4).

According to the co-author relationship, diagram was drawn (Figure 5). The color in the figure indicates the researcher's area or research area. Each node represents a researcher. The size of the node represents the number of documents. The connection between the nodes represents a cohesive relationship between the researchers. The thicker line, indicates that the number of co-authors between the two researchers is greater.

\section{Discussion}

With the level of diagnosis and treatment increasingly improving, the early diagnosis rate of colorectal cancer has been significantly improved. The innovation and development of minimally invasive technology and the reform of concept of diagnosis and treatment make local recurrence rate after surgery reducing to $5 \%{ }^{[13]}$, The medical workers in the field of colorectal cancer in China have achieved remarkable results during the past 10 years. However, due to a large population base in China, there are still nearly 400,000 new patients and nearly 200,000 deaths every year ${ }^{[14]}$. The situation is still grim. China's clinical research started late, and the important aspects of the research lacked experience and insufficient attention. There is still a big gap between China and other countries such as Japan, South Korea, Europe and America ${ }^{[15,16]}$.

At present, clinical RCT research hotspots include the debate between laparoscopic and open surgery [17], the advantages and disadvantages of the "Wait and See" strategy during the pathological complete remission after neoadjuvant chemoradiotherapy ${ }^{[18] ;} 3$ months or 6 months for adjuvant chemotherapy [19]; the feasibility of Complete transanal total mesorectal excision (TaTME) ${ }^{[20]}$ and the best chemotherapy sequence of neoadjuvant chemotherapy for advanced rectal cancer. All these hotspots are most lead by the aboard. However Chinese researchers and institutions seldomly participate these hotspots. Nowadays domestic clinicians are gradually aware of this situation and are actively carrying out clinical research on evidence-based medical evidence.

China clinicians have a wealth of medical information. Multi-center RCTs can use this advantage to get some high-quality clinical data. For example, the RELARC study of the scope of laparoscopic right colon cancer lymphatic dissection led by Peking Union Concord Hospital is being carried out in strict accordance with the implementation standards. The study conducted multiple rounds of argumentation and consideration for the surgical risks and benefits of Complete mesocolic excision (CME). For example, the FOWARC study led by the Sixth Affiliated Hospital of Sun Yat-sen University ${ }^{[21]}$ selected patients with stage II-III rectal cancer and discussed the necessity of receiving oxaliplatin after receiving neoadjuvant therapy, and obtained FOLFOX plus Radiotherapy has the best effect, but pure FOLFOX chemotherapy 
can achieve similar down-regulation effects with fewer complications. Although the long-term survival is still being followed up, the preliminary results have already inspired researchers at home and abroad.

Through the statistical analysis of the included literatures, the top ten research institutions in the publications are in the United States, the United Kingdom and Canada. China is not among the top ten research institutions. In the field of colorectal cancer, Sun Yat-sen University is ranked 20th in the forefront of clinical research in China. 7 of the 15 most cited papers were from Lancet and its subdistributions. The article focuses on colonoscopy for colorectal cancer, surgical treatment of metastatic colorectal cancer, surgical procedures, first-line, second-line chemotherapy, and targeted therapy, such as open and laparoscopic surgery, the safety and efficacy of panitumumab, bevacizumab and cetuximab. Key words co-occurrence map shows that age, surgery, drug therapy, targeted therapy, neoadjuvant, pathology, comparative study, treatment outcome, disease-free survival, quality of life and other keywords occur frequently. At present, research hotspots focus on colorectal cancer screening, diagnosis and treatment concepts, surgical methods, choice of drug treatment methods, and evaluation of treatment outcomes and quality of life.

A co-occurrence map of co-authors shows that most of the researchers who are active in international multi-center research are from Europe, America, Japan and South Korea. These co-authorships of different countries are relatively close and extensive, and researchers from Asian countries such as Japan and South Korea is less co-authored with European and American scholars.

In addition, van custsem, cunningham, rivera, kim, morriya, etc. have a large number of publications and close relationship, and explore the hotspots of clinical research on colorectal cancer. They are very likely to be the authority in this field. The number of literatures related to colorectal cancer published by the Chinese ranks first, but the RCT study ranks third, with fewer multicenter RCTs. The reason may be that the cost of RCT is high [22], the research team is immature, the research design ideas and research endpoints are unreasonable, and the data collection is irregular. The key links in the implementation process are also complex, and the research team needs to face a series of questions such as medical ethics review and good clinical practice (GCP). The development of multi-center high-quality RCT research requires sufficient and large amount of research funding and government agencies to support the project. All researchers need to unite and forge ahead, persevere and cooperate sincerely, and the exchanges and cooperation between scientific research institutions also play an important role. Therefore, domestic researchers should pay attention to the various key aspects of RCT research, truthseeking, pragmatic, and standardize all aspects of clinical RCT research, so that clinical research maintains high accuracy and credibility.

Limitations of this paper: Only Pubmed and Web of science English databases are searched. There are few documents in other languages included in the database, and there may be publication bias; The quality of the literature is not evaluated by the methodological quality evaluation tool. 
In summary, the results of bibliometric analysis of colorectal cancer-related RCTs in the past 10 years at home and abroad show that high-quality randomized controlled trials are increasingly favored by top international journals. Although China's clinical research has achieved initial results, there are still large gaps with Europe and America. Domestic researchers should gradually implement the standardization and accuracy of clinical trials, and strengthen multi-center cooperation at home and abroad while emphasizing quality control, and implement higher quality colorectal cancer-related RCT research to promote clinical research in colorectal field in China.

\section{Abbreviations}

RCTs: randomized controlled trials

NCCN: National Comprehensive Cancer Network

ESMO: European Society for Medical Oncology

\section{Declarations}

\section{Ethics approval and consent to participate}

This study outlines a Bibliometric analysis of secondary data and, hence, does not require ethical approval or consent to participate.

\section{Consent for publication}

Not applicable

\section{Availability of data and materials}

The data and materials are from the PubMed囚https://pubmed.ncbi.nlm.nih.gov囚and Web of Science \https://www.webofknowledge.com》

\section{Authors' contributions}

C-YW and J-HH designed this study. S-CZ and X-WL performed the search and collected data. J-JZ rechecked data. ZG and QZ performed analysis, X-HL re-checked. S-CZ and X-WL wrote the manuscript, CYW and $\mathrm{J}-\mathrm{HH}$ reviewed the manuscript.

Study conception and design- CYW, JHH; Acquisition of data- SCZ; Analysis XWL; Interpretation- JJZ, ZG, QZ; Drafting of manuscript XHL; Critical revision- SCZ, XWL.

\section{Conflicts of interests}

The authors declare that there was no conflict of interests in this study. 


\section{Funding}

This work was supported by the Wu Jie Ping Medical Foundation Clinical Research Special Fund [320.2710.1836], the Henan University Graduate Student "talent plan" [SYL18060141], basic research project of key scientific research projects in colleges and universities[17B320003] and key research and development and promotion of special scientific and technological research of Henan [182102310544]. The funders were not involved in the design of the study or the decision to submit the manuscript for publication nor were they involved in aspects of the study conduct. The views expressed in this manuscript are those of the authors and may not be understood or quoted as being made on behalf of, or as reflecting the position of, the funder(s) or any institution.

\section{References}

[1] Siegel RL, Miller KD, Fedewa SA, Ahnen DJ, Meester RG, Barzi A, Jemal A. Colorectal cancer statistics, 2017. CA: a cancer journal for clinicians. 2017 May 6;67(3):177-93.

[2] Chen W, Zheng R, Baade PD, Zhang S, Zeng H, Bray F, Jemal A, Yu XQ, He J. Cancer statistics in China, 2015. CA: a cancer journal for clinicians. 2016 Mar;66(2):115-32.

[3] Nordlinger B, Sorbye H, Glimelius B, Poston GJ, Schlag PM, Rougier P, Bechstein WO, Primrose JN, Walpole ET, Finch-Jones M, Jaeck D. Perioperative chemotherapy with FOLFOX4 and surgery versus surgery alone for resectable liver metastases from colorectal cancer (EORTC Intergroup trial 40983): a randomised controlled trial. The Lancet. 2008 Mar 22;371(9617):1007-16.

[4] Atkin WS, Edwards R, Kralj-Hans I, Wooldrage K, Hart AR, Northover JM, Parkin DM, Wardle J, Duffy SW, Cuzick J, UK Flexible Sigmoidoscopy Trial Investigators. Once-only flexible sigmoidoscopy screening in prevention of colorectal cancer: a multicentre randomised controlled trial. The Lancet. 2010 May 8;375(9726):1624-33.

[5] Grothey A, Van Cutsem E, Sobrero A, Siena S, Falcone A, Ychou M, Humblet Y, Bouché O, Mineur L, Barone C, Adenis A. Regorafenib monotherapy for previously treated metastatic colorectal cancer (CORRECT): an international, multicentre, randomised, placebo-controlled, phase 3 trial. The Lancet. 2013 Jan 26;381(9863):303-12.

[6] Tol J, Koopman M, Cats A, Rodenburg CJ, Creemers GJ, Schrama JG, Erdkamp FL, Vos AH, van Groeningen CJ, Sinnige HA, Richel DJ. Chemotherapy, bevacizumab, and cetuximab in metastatic colorectal cancer. New England Journal of Medicine. 2009 Feb 5;360(6):563-72.

[7] Baxter NN, Goldwasser MA, Paszat LF, Saskin R, Urbach DR, Rabeneck L. Association of colonoscopy and death from colorectal cancer. Annals of internal medicine. 2009 Jan 6;150(1):1-8.

[8] Hecht JR, Mitchell E, Chidiac T, Scroggin C, Hagenstad C, Spigel D, Marshall J, Cohn A, McCollum D, Stella P, Deeter R. A randomized phase IIIB trial of chemotherapy, bevacizumab, and panitumumab 
compared with chemotherapy and bevacizumab alone for metastatic colorectal cancer. J Clin Oncol. 2009 Feb 10;27(5):672-80.

[9] Maughan TS, Adams RA, Smith CG, Meade AM, Seymour MT, Wilson RH, Idziaszczyk S, Harris R, Fisher D, Kenny SL, Kay E. Addition of cetuximab to oxaliplatin-based first-line combination chemotherapy for treatment of advanced colorectal cancer: results of the randomised phase 3 MRC COIN trial. The Lancet. 2011 Jun 18;377(9783):2103-14.

[10] Peeters M, Jay Price T. Randomized phase III study of panitumumab with fluorouracil, leucovorin, and irinotecan (FOLFIRI) compared with FOLFIRI alone as second-line treatment in patients with metastatic colorectal cancer.

[11] Folprecht G, Gruenberger T, Bechstein WO, Raab HR, Lordick F, Hartmann JT, Lang H, Frilling A, Stoehlmacher J, Weitz J, Konopke R. Tumour response and secondary resectability of colorectal liver metastases following neoadjuvant chemotherapy with cetuximab: the CELIM randomised phase 2 trial. The lancet oncology. 2010 Jan 1;11(1):38-47.

[12] Verwaal VJ, Bruin S, Boot H, van Slooten G, van Tinteren H. 8-year follow-up of randomized trial: cytoreduction and hyperthermic intraperitoneal chemotherapy versus systemic chemotherapy in patients with peritoneal carcinomatosis of colorectal cancer. Annals of surgical oncology. 2008 Sep 1;15(9):242632.

[13] Huang HY, Shi JF, Guo LW, Bai YN, Liao XZ, Liu GX, Mao AY, Ren JS, Sun XJ, Zhu XY, Wang L. Expenditure and financial burden for the diagnosis and treatment of colorectal cancer in China: a hospital-based, multicenter, cross-sectional survey. Cancer Communications. 2017 Dec;36(1):1-5.

[14] Pan R, Zhu M, Yu C, Lv J, Guo Y, Bian Z, Yang L, Chen Y, Hu Z, Chen Z, Li L. Cancer incidence and mortality: a cohort study in China, 2008-2013. International journal of cancer. 2017 Oct 1;141(7):131523.

[15] Zavoral M, Suchanek S, Majek O, Fric P, Minarikova P, Minarik M, Seifert B, Dusek L. Colorectal cancer screening: 20 years of development and recent progress. World journal of gastroenterology: WJG. 2014 Apr 14;20(14):3825.

[16] Neuman HB, Park J, Weiser MR. Randomized clinical trials in colon cancer. Surgical Oncology Clinics. 2010 Jan 1;19(1):183-204.

[17] van der Pas MH, Haglind E, Cuesta MA, Fürst A, Lacy AM, Hop WC, Bonjer HJ, COlorectal cancer Laparoscopic or Open Resection II (COLOR II) Study Group. Laparoscopic versus open surgery for rectal cancer (COLOR II): short-term outcomes of a randomised, phase 3 trial. The lancet oncology. 2013 Mar 1;14(3):210-8. 
[18] Dattani M, Heald RJ, Goussous G, Broadhurst J, São Julião GP, Habr-Gama A, Perez RO, Moran BJ. Oncological and survival outcomes in watch and wait patients with a clinical complete response after neoadjuvant chemoradiotherapy for rectal cancer: a systematic review and pooled analysis.

[19] Grothey A, Sobrero AF, Shields AF, Yoshino T, Paul J, Taieb J, Souglakos J, Shi Q, Kerr R, Labianca R, Meyerhardt JA. Duration of adjuvant chemotherapy for stage III colon cancer. New England Journal of Medicine. 2018 Mar 29;378(13):1177-88.

[20] Wolthuis AM. Transanal total mesorectal excision international registry results of the first 720 cases.

[21] Deng Y, Chi P, Lan P, Wang L, Chen W, Cui L, Chen D, Cao J, Wei H, Peng X, Huang Z. Modified FOLFOX6 with or without radiation versus fluorouracil and leucovorin with radiation in neoadjuvant treatment of locally advanced rectal cancer: initial results of the Chinese FOWARC multicenter, open-label, randomized three-arm phase III trial. J Clin Oncol. 2016 Sep 20;34(27):3300-7.

[22] Bothwell LE, Greene JA, Podolsky SH, Jones DS. Assessing the gold standard-lessons from the history of RCTs. N Engl J Med. 2016 Jun 2;374(22):2175-81.

\section{Figures}

7685 records identified through database searching

PubMed (3146)、Web of:Science (4539)

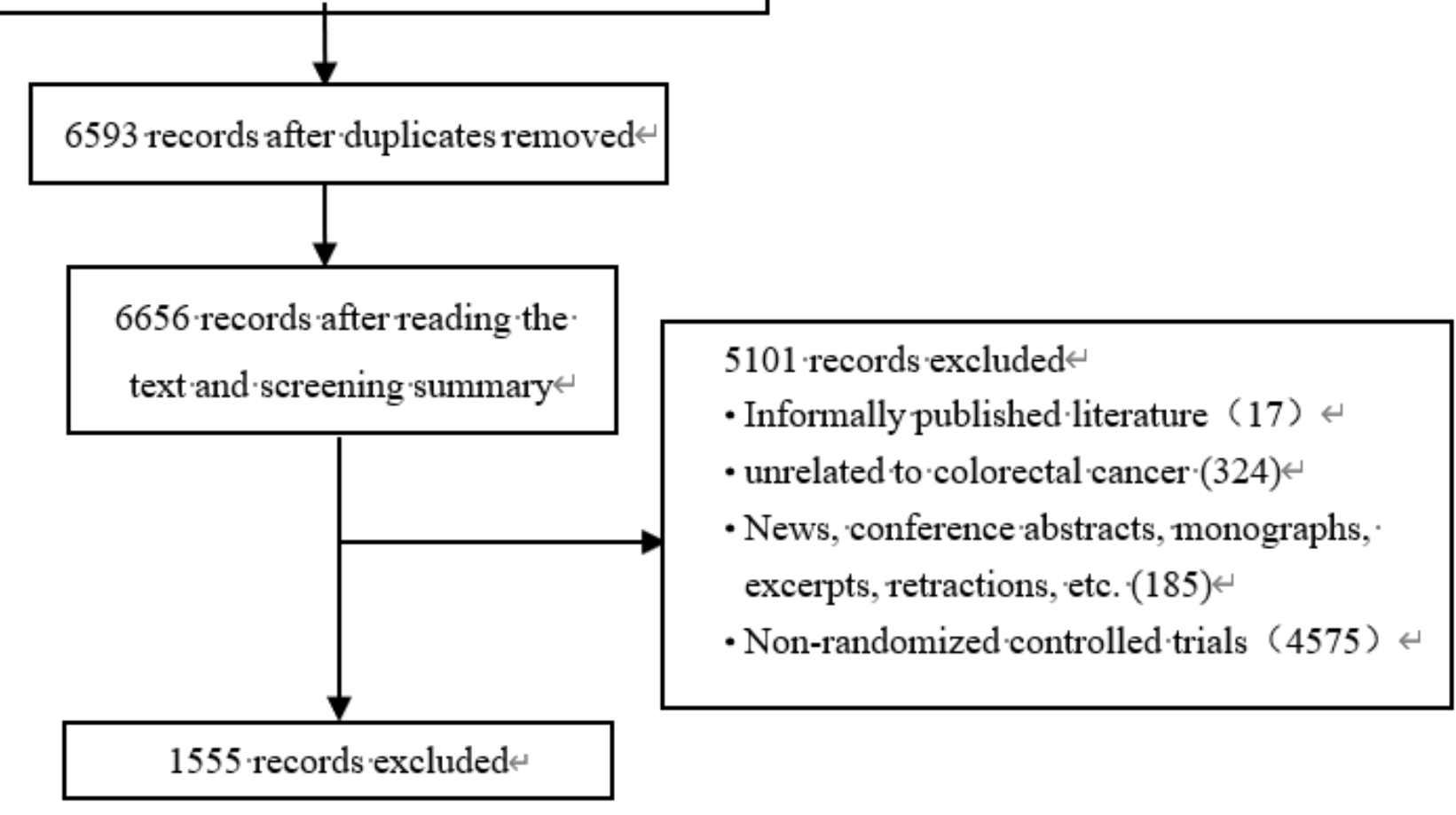

Figure 1 
Results of the literature search.

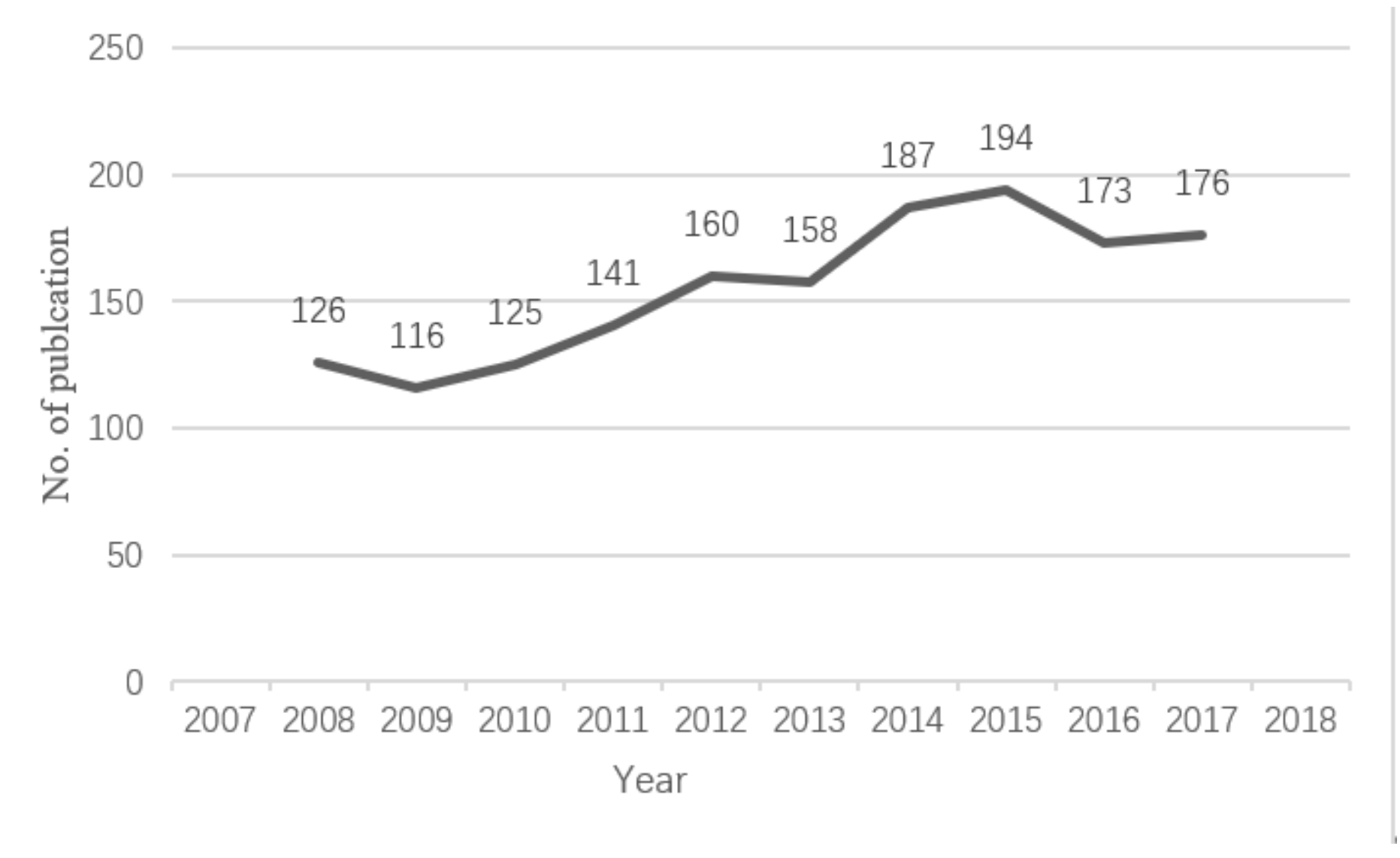

Figure 2

Year of publication. 


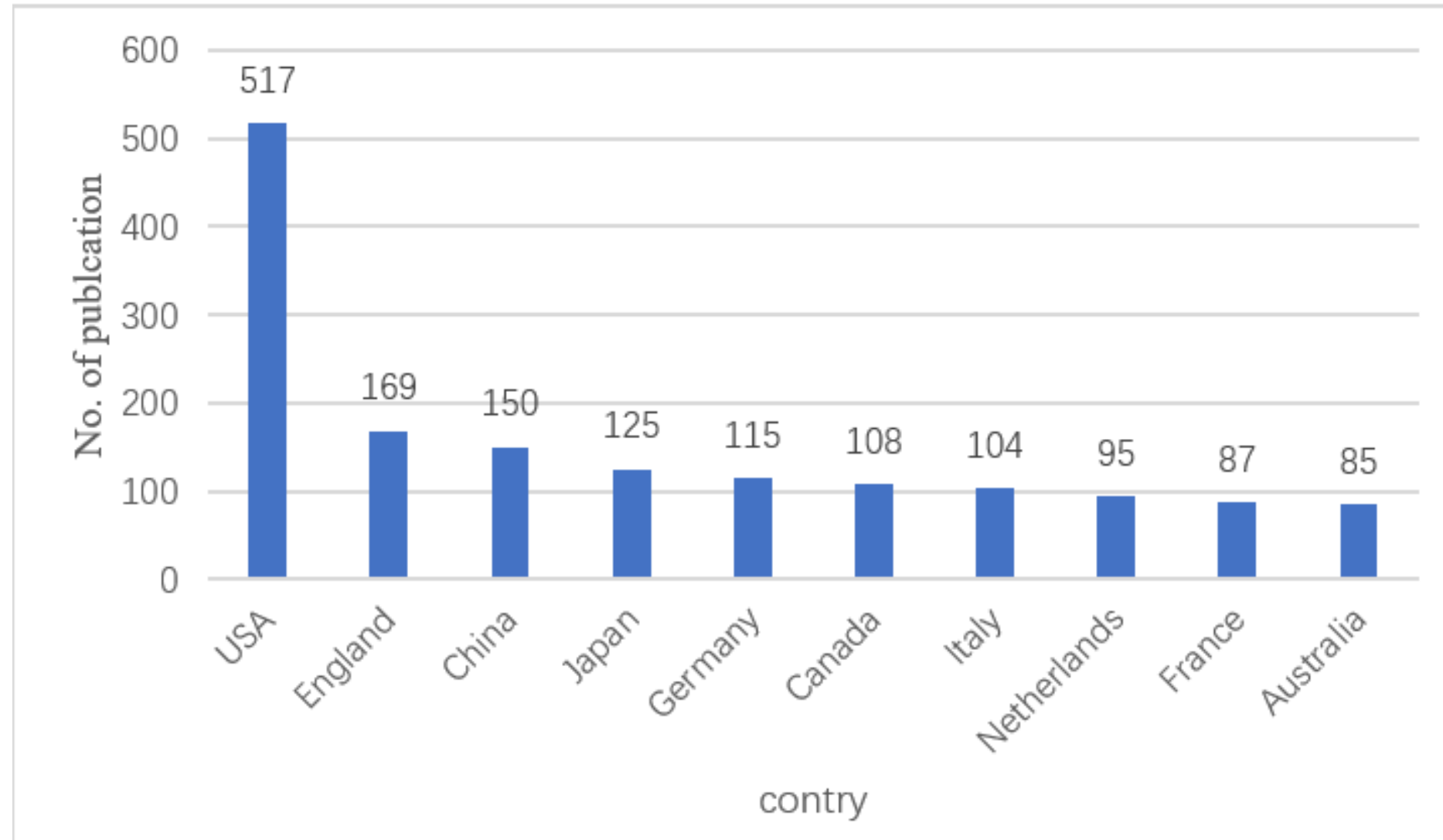

Figure 3

Origin of RCTs. Top 10 countries with RCT literatures. 


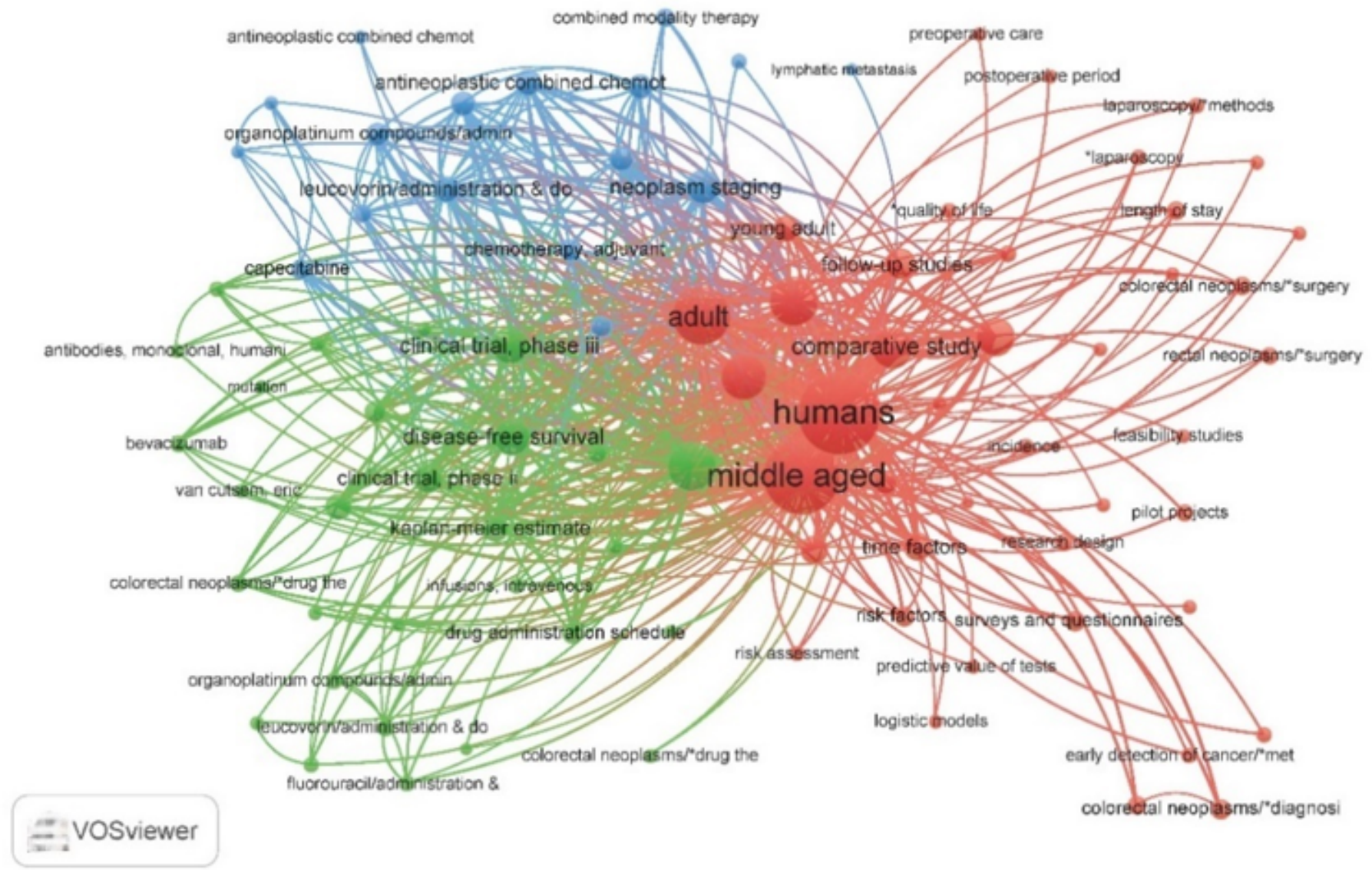

Figure 4

Network visualization using keywords 


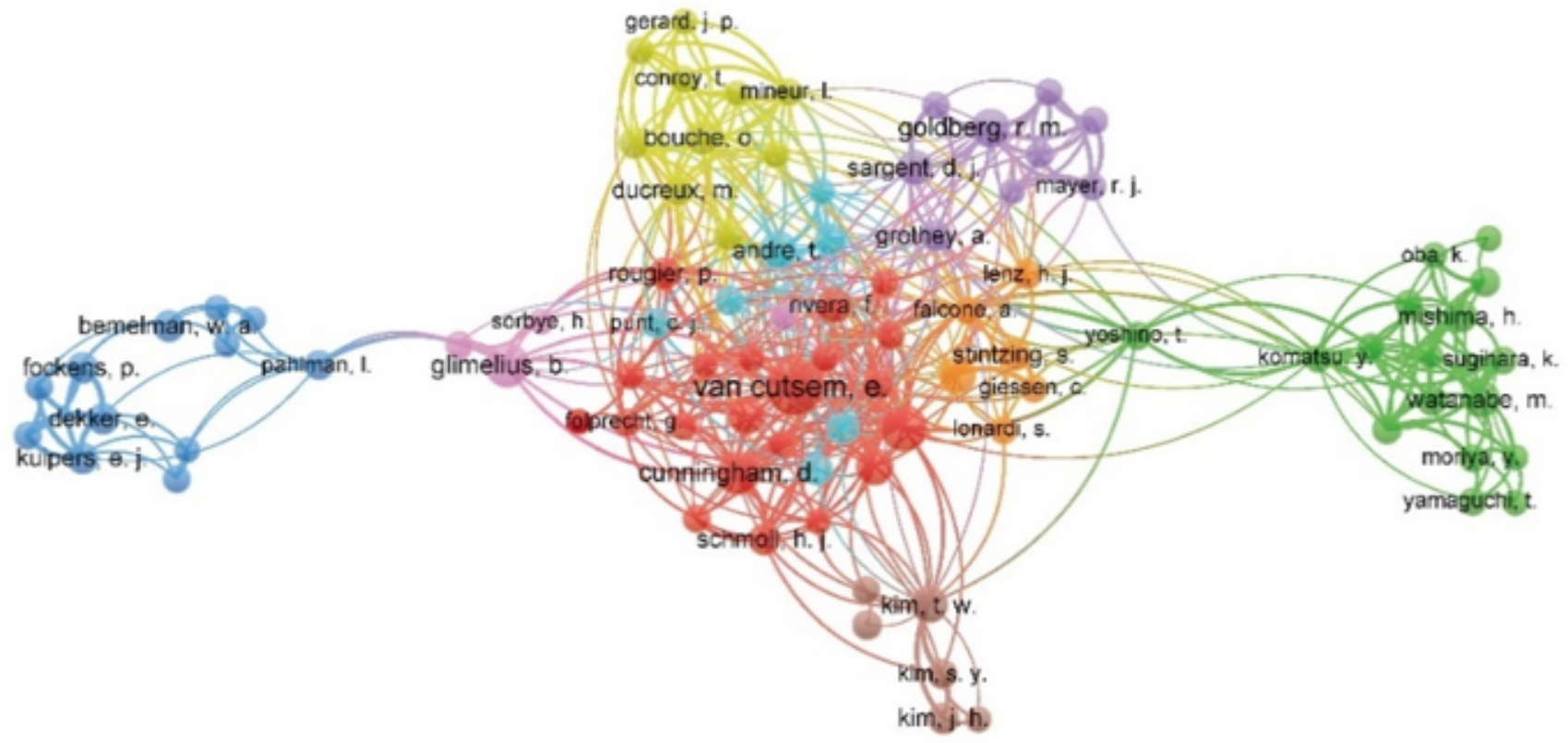

a:vOSviewer

\section{Figure 5}

Network visualization using researcher and co-author

\section{Supplementary Files}

This is a list of supplementary files associated with this preprint. Click to download.

- Reportingchecklist.docx 